International Journal of Linguistics, Literature and Culture
Available online at https://sloap.org/journals/index.php/ijllc/
Vol. 4, No. 6, November 2018, pages: 53 62
ISSN: 2455-8028
https://sloap.org/journals/index.php/ijllc/article/view/407

\title{
Textual Representation of Identity in Classroom Discourse
}

\author{
La Ode Alfin Haris Munandar ${ }^{\text {a }}$ \\ Lalu Muhaimi ${ }^{\text {b }}$ \\ Nawawi $^{\mathrm{c}}$
}

\section{Article history:}

Received: 9 July 2018

Accepted: 30 September 2018

Published: 26 November 2018

\section{Keywords:}

classroom discourse;

conjunction structures;

identity types;

identity;

interlanguage;

\begin{abstract}
This research is aimed to find out the types of identity which are reflected through the language used in classroom context in which the spoken language will be analyzed in order to find out the words or phrases or sentences that represent certain identity as well as the frequency of occurrence of each identity. The model for identity categorization on this research is based on the work of Vignoles et al., (2011) in which the identity is categorized into personal, relational, collective, and material identity. Moreover, in analyzing the language that is used to state identity, this research used the work of Bloome, et al., (2005) in which they have found that in order to imply their identities, the students used a variety of linguistic means such as conjunction structures, authoritative figures, specific lexical items including names, complementary pairs, places, and highly evaluated items. This research used descriptive-qualitative design. The object of this research was the undergraduate students in Mataram University in academic year 2016/2017. Four classes were chosen for the samples. The data were gathered through two processes that were recording and transcription. Based on the analysis of the findings, all four categories of identities were found with $25.5 \%$ ( 25 occurrences) for personal identity, $47 \%$ (46 occurrences) for relational identity, $26.5 \%$ (26 occurrences) for collective identity, and $1 \%$ (1 occurrence) for material identity. The frequency of occurrence was dominated by relational identity and collective identity in the second place. This might be caused by the cultural value orientation in which the samples came from collectivistic society. The finding also indicated that not only the identities were represented through what has been found by Bloome et al., (2005), but also through the use of greetings, certain expression, interlanguage, as well as nonverbal act.
\end{abstract}

\footnotetext{
a Mataram University, Indonesia

${ }^{\mathrm{b}}$ Mataram University, Indonesia

${ }^{\mathrm{c}}$ Mataram University, Indonesia
} 


\section{Author correspondence:}

La Ode Alfin Haris Munandar,

Mataram University, Indonesia

Email address: harisalfin91@gmail.com

\section{Introduction}

Discourse can be understood as language-in-use which is "affected by the context of its use" (Rhymes, 2008:12). Hence, the study of the way language is affected by its use is known as discourse analysis. Since language is affected by various contexts, it brings the fourth subcategory of discourse analysis such as classroom discourse analysis where the language used in the context of the classroom becomes the core or focus of the analysis.

Furthermore, many types of research have been conducted an analysis on classroom discourse and one of these is the research conducted by Bloome et al., (2005) in which they argue that classroom should not be configured merely as a room where teaching and learning processes are conducted but rather as an environment where the teacher 'acting on' the students by choosing and deciding the activities or topics in which the students engage in the classroom. The students also 'acting on' the teacher by participating in activities provided by the teacher. Here, the classroom should be seen as an environment where teacher and students 'act together' in building their 'classroom world'.

Moreover, Bloome et al., (2005) argued that within this 'classroom world', teacher and students state and build their identity through language use. However, the identity which has been built and labeled to a certain individual is not permanent, it continues to evolve and shift from one identity to another as the time goes on. In addition, Fearon (1999), claimed that identity is not something which human are born with, rather it is socially constructed in which the process of constructing identity takes time during the growth of an individual in a social environment. Fearon (1999), the claim is based on the fact that identity falls into the social category. This claim is supported by Vignoles et al., (2011), who argued that a certain characteristic of an individual does not necessarily give an identity for that individual. For example, having a particular skin color or being intelligent does not necessarily give someone an ethnic identity or the identity of an intellectual. Characteristics such as these "only become part of identity to the extent that they are interpreted and infused with the personal and social meaning" (Vignoles et al., 2011:2-3).

In their discussion, Bloome et al., (2005) exemplify the ways African-American students accomplished their social identities and their evolution through "a variety of linguistic means, including conjunction structures; parallel structures across utterances; placing authority figures in the active case; using specific lexical items, including names, complementary pairs, places and highly valued items; and combination of these linguistic strategies" (Bloome et al., 2005:120). In addition, recent studies on identity have found out that social identity contained issues related to intergroup behavior (Tajfel \& Turner, 1986), prejudice and discrimination (Licata et. al., 2011), teachers' power relation and identity change (Overton, 2006), as well as the development of public opinion (Mangum and Block Jr., 2017). All those suggest that studying identity is important to conduct. Thus, this study aims to contribute to the scientific inquiry and body of knowledge on the textual representation of identity in classroom discourse in which the representation of identity is analyzed through the use of language. The identities that have been found are categorized based on identity categorization purposed by Vignoles, et al., (2011) which are individual or personal, relational, and collective identity. Then, each of this identity is counted based on its frequency of occurrence. Finding the frequency of occurrence is directed to find out the social background of the member of the classroom that is cultural value orientation.

\section{Theory}

Turner (1982) defined social identity as purely 'cognitive' processes. Based on this view, identity is seen as part of cognitive systems in which it could change, shift or develop depending on the social condition. Scholars such as Norton \& Tohey (2011) and Bloome et al., (2005) have been analyzed the moment-by-moment of identity shift within the classroom context. Furthermore, the socio-cognitive perspective was used in this current study to analyze the representation of identity in which the cognition was seen as one of the crucial aspects that affect human communication. According to Van Djik (2018), cognitive processes take place in the human mind which operate on specific cognitive structures known as 'mental representation'. Van Djik (2018), added that all human action and interaction are controlled by cognitive processes and mental representations. This means that the word choice is also a product of cognitive processes and mental representation which then provide a bridge to analyze the identity of 
human being since identity, traditionally, can be understood as 'knowing about oneself' in which 'knowing' is a part of cognitive processes (Van Djik, 2018). Thus, this current study analyzed the words, phrases, or sentences that were used to represent identity in a classroom context.

\section{Materials and Methods}

This study used descriptive-qualitative as its research design, the most important reason for using descriptivequalitative design is that this design is the right way to explore everyday behavior. Following the procedures of applying descriptive-qualitative principles introduced by Flick (2009) in which he argues that it might be appropriate to be used in analyzing local, temporal, and situational phenomena.

As mentioned earlier that this study focuses on identity representation on classroom discourse, it requires the source of the data from a classroom in which the participants come from a various social background. For this reason, the data within this study will be taken from recorded classroom interaction performed by the students of the undergraduate program of English department in Mataram University (UNRAM) since it is one of the most prestigious universities in West Nusa Tenggara, it makes the students and the lecturers come from various social backgrounds and are expected to provide reliable data for this study.

The data were collected through observation, video recording, transcription, and categorization. The observation was intended to decide the classroom that became the source of the data. The factor that determines which class to be analyzed was the frequency of the conversation of both teacher and students. Thus, the classroom in which the teacher dominates all the talk will not become the subject of this research. Note taking will also be used during this observation which is intended to support the video recording which will be used for the next step of collecting the data. Video recording was intended to get the real language used by the teacher and students, as well as capturing the turn during the conversation in a classroom context. In another word, video recording was not only intended to get the language, but also to capture who is talking in a certain time. Furthermore, the recording technique was supported by the note taking which was the result of the observation. All the conversation was transcribed and identified. The process of identification will be used to categorize the data into word/phrase/sentences so that the process of analyzing the data could be done in an easier fashion.

The method that was used to analyze the data in this study was an explanatory method in which it was not intended only to find out the types of the identity and the number of their occurrence, but also to find out the reason behind it. Thus, the procedures for analyzing the data were basic analysis, data calculation, and interpretation.

The first step of analyzing the data was basic analysis in which the data that has been categorized into word, phrase, and sentence were classified based on the identity they belong using the work of Vignoles et al., (2011), in which identity is categorized into individual or personal, relational, collective, and material identity. This step was intended to fill the first research objective which is to find out the types of identity that are represented in classroom discourse. The next step of data analysis was to interpret the word, phrase, or sentence that was used to state the identity based on Van Dijk's (1993; 2018), socio-cognitive view which assumes that the use of language is determined by the cognition of the speaker in which the cognition is heavily affected by the social interactions. This interpretation is intended to describe certain words that are used to represent an identity in classroom discourse in which those words may not have any sense of identity in a different context. Once the data has been classified into the types of identity, it will be calculated and interpreted in order to find out the dominant identity and the reason for its dominance.

\section{Results and Discussions}

\subsection{Types of Identity}

In categorizing the types of identity in this research, the model used is the types of identity purposed by Vignoles et al., (2011) in which identity is categorized into four categories which are individual, relational, collective, and material identity. Each of this identity is marked by various characteristics such as goals, values, beliefs, etc. for individual identity, relation with other people for relational identity, the processes of the identity at hand for collective identity, and material items for material identity.

Munandar, L. O. A. H., Muhaimi, L., \& Nawawi, -. (2018). Textual representation of identity in classroom discourse. International Journal of Linguistics, Literature and Culture, 4(6), 53-62. 
In this research, the representation of each identity is analyzed through the language used in a classroom context. In doing so, the conversations among the classroom members were recorded and transcript which then analyzed based on the sense of identity that holds by the sentences, phrases, or words. In other words, the identities of the members of the classroom were traced through their use of language.

a) Individual Identity

Individual identity in this research was seen through its characteristic in which it represented the characteristic, belief, values, goals, desired, future expectation, and overall life story of the speaker. In short, any forms of language which represent these characteristics were categorized into the marker of individual identity.

The results indicated that personal identity was represented in any forms. One of them was the use of the declarative sentence. The declarative sentence can be understood as the type of sentence that is used to state facts or opinions. It is the form of sentence which is most commonly used in a conversation. Thus, the speaker's identity can be traced through the use of this sentence. For instance,

Extract 1

1) I think it is very rude to ask that question

2) I think it is good for us to leave our friends' privacy and secret

3) I am not familiar with this one

The fact that the speakers think that it is rude in extract 1 (a) and good in extract 1(b) reflected the way the speakers think which could be the standards for their behavior and decision-making in social context such as in extract 1 (c), the speaker's unfamiliarity with the problem at hand might results in asking for help from the other member of the classroom. Thus, the sentences in extract 1 are categorized into the representation of an individual or personal identity. However, there were some cases in which the sense of identity did not come from the whole sentence, instead, it came from some part of the sentences such as on the extract 2 below.

\section{Extract 2.}

1) I have to give a presentation about the teacher's professional development

2) I arrive at home at 11 A.M. and cook

The sense of identity in extract 2 (b) comes from the word 'cook'. The ability to cook indicated that the speakers could take care of his/her own food which gives a sense of independence. As for extract 2 (a), there is an interesting finding here in which if the focus is on the 'give a presentation' it would give a sense of relational identity since the one who gives presentation must be a presenter and this presentation must be presented to audiences. The relation of presenter and audience indicated relational identity. However, if the focus is one 'teacher's professional development' it raised the sense of individual or personal identity. Since the one who gives a presentation in front of a teacher might be the one has more knowledge or experiences regarding teacher-ship.

Furthermore, the results indicated that individual or personal identity did not only come from the speakers but also came from the way the audiences react toward the speaker's sentence. As in the following Extract,

Extract 3.

(a presenter tried to explain his material)

1) Presenter : This is the best quote I've ever had

Audience : (giggling)

2) Presenter : The stimulation like aaaaa stimulation

Audience : (giggling)

3) Presenter : I have read a book About Ali bin Abi Thalib

Audience : Weiiiiiiis

Presenter : But I forget what it says

Audience : (laugh)

Presenter : Maybe aaaa in mind maybe little I can remember aaaa well aaa let's just forget about Ali

Audience : (laugh louder) 
In this exact, the presenter did not try to make a joke or to be funny, in fact, the presenter seriously tried to explain his material by giving example and paraphrase his previous statement into a simpler one. However, the response from the audiences in which the audiences laughed during his presentation made the sense of funny person came up. So, it could be said that personal or individual identity can also be seen through the reaction of the audience.

The last form of the representation of personal or individual identity is in the form of expression and the act of refusing or neglecting or what is known in Gricean implicature as opt-out in which the speaker chooses to refuse in contributing on the conversation.

Extract 4.

(During the question and answer section)

1) Presenter : Jagad may explain why children throw away their parents

Jagad : No, You should answer that

Presenter : (Refusing to answer)

2) Speaker $A$ : What game do you play? I play the game too

Speaker B : I Play Mobile Legend

Speaker A : Noob! (laugh)

On the extract 4 (a) the presenter chose to neglect the question even after her member suggested to answer that question. This nonverbal language in which the presenter chose not to answer the question even it was part of his role as a presenter to answer questions from audiences gave a sense of lack of knowledge, lack of preparation, or even ignorance. Thus, this act is categorized into the representation of the presenter's personal or individual identity.

Apparently, for the extract 4 (b), the word 'noob' was used as an expression toward people who do not know how to play a certain game. By expressing this expression toward Speaker B, speaker A indicated that he saw himself as a good player on the game being talked.

b) Relational Identity

Relational Identity deals with the relations of an individual with other people as well as the role of an individual in a social context. In this research, those relations were not only with the members of the classroom but also with other people outside the class. If those external relations were represented on the language use used by the member of the classroom, then it is considered as their relational identity. Relational identities that have been found in this research were also represented through different types of sentences such as declarative, imperative, exclamation. The following extract indicated the way of each type of sentence was used as the identity marker of its speaker.

Extract 5

1) We are going to have our lesson today until 10

2) Find your pair and say the time

3) Ok, now start telling your time to your partner

In the extract above, it can be seen that each sentence served a different function. Extract 5 (a) indicates the explanation regarding the duration of the class, 5 (b) is an instruction to work together, and 5 (c) is an order to start an activity. Taken together, the extract 5 consist of explanation, instruction, and order. In classroom context, the one that may arrange the duration of the class, giving instruction regarding the activity within the class, and giving orders to all the classroom members are the teachers even though there are possibility in which a student might order or instruct his/her fellow students, the effect of an order or instruction that comes from a student will possibly not affect the whole member of the class, at max it might affect his/her own member if this student belongs to a group or it may affect only the audience if this student is a presenter.

Furthermore, the representation of identity was also represented through the use of repetition of the same form of interrogative sentences. The sense of identity in this sentence did not come from the sentence itself; rather it came from the repetition as in the extract 6 below.

Extract 6

(Miscommunication between teacher and students regarding the schedule of the class)

Did he tell me about the new schedule?

Munandar, L. O. A. H., Muhaimi, L., \& Nawawi, -. (2018). Textual representation of identity in classroom discourse. International Journal of Linguistics, Literature and Culture, 4(6), 53-62. https://doi.org/10.21744/ijllc.v4n6.407 
So that's why I'm kind of imagining 'why didn't he tell me about the new schedule'

Did he tell me about the new schedule?

Did I have to wait?

Yes, I have to wait because he did not tell me about the new schedule

Now I'm saying 'you should have told me'

This is the way we express

The repetition of the same question in this context is indicated as the initiation for teaching activities which in this context was teaching about the way of expressing. If the integrative sentence was not repeated, it might be seen as a complaint. However, it was repeated and so the sense of teaching came up in which the teaching is the role of a teacher. Thus, being a teacher is considered a relational identity since, in order to perform teaching, there should be students being thought.

The next markers for relational identity were figures such as father, mother, siblings, and friends as in the extract 7 below. Each of the sentences in extract 7 indicated that the speaker has a relationship with other people

\section{Extract 7}

1) I would like to introduce my friends

2) My father said that I have to give my last name to my children

3) My mother, my little brother, and I are happy with our condition

The last markers for relational identity that have been found in this research were the use of conjunction in which the speaker indicated a relationship with the one being talked by using 'with'. The use of 'with' as a marker for relational identity can be seen on sentence code T1.TT1.1 in which the speaker said 'I have discussed with your captain and what I've understood from your captain was that we would start our class at 8.30'. The 'with' in this sentence was clearly indicated that there was a relation between the speaker and the captain, this relation than revealed on the next part of the sentence that is 'we would start our class at 8.30'. In this context, the people involved in the discussion regarding the schedule of a class must be taught and students.

\section{c) Collective Identity}

The collective identities in this research were not only categorized based on the sense of its collectivity but also based on the feelings, believes, and attitudes that result from people's identification with the groups and social categories to which they belong to.

The results indicated that there were various ways in which the members of the class that has been analyzed represented their identity such as the Islamic greetings. The repetition of this greeting and its response were quite often which indicated that the majority of the members of the classes were Muslim. Being a Muslim might be indicated as an individual or personal identity. However, the greeting here was seen from the content term in which the speakers and the listener were members of a certain religion which is Islam. Furthermore, the speaker said an activity which might only belong to Islam and might be done only by pious Muslim.

\section{Extract 8}

You may also add 'most of the time but sometimes earlier at 4 to perform Qiyamullail or to perform the night prayer

The sense of collectivity from this exact did not come from the fact that 'Qiyamullail' or 'the night prayer' is the way Muslim pray, but it came from the fact that this prayer mostly done by pious Muslim. Thus, it was indicated from this sentence that the speakers were belong to the group of pious Muslim in which they perform the 'night prayer'. From this description, it could be seen that within a large context of collectivity, there is also a smaller collectivity.

Moreover, there was a statement in which the speakers mentioned about having more wives but no more than four. This statement is believed to be based on the verse of Qur'an which is the holy book for Islam.

Furthermore, the markers for collectivity were found on the use of interlanguage in which the language differs from native and target language but shares the features of both. Interlanguage commonly occurs during a language acquisition and thus in this context, the occurrence of interlanguage marked the speaker as a language learner. The occurrences of interlanguage are shown on the following extract. 
Extract 9

1) This species this kangaroo is aaaa to be (undecipherable) than the red kangaroo

2) We can make an example sentence is aaa

d) Material Identity

Material identity can be identified through the representation of material items such as the way people dressed. However, in this research material identities were taken into account only if it is textualized or represented on the language use. Thus, there was only one occurrence of Material Identity which can be seen on the following extract.

Extract 10

Teacher : You missed the first two classes. Try not to miss too many classes because if your attendance is less than $75 \%$, you will be considered to drop the course

Student $\quad$ : Yes, Last week I broke my cell phone so I didn't know the new schedule

\subsection{The Dominant Identity}

The dominant identity here is understood as the most dominant identity that was represented in the classroom context and its dominance was measured through the frequency of its occurrence.

Table 1

Types and percentage of occurrence of each identity

\begin{tabular}{llll}
\hline No & Types of Identity & Frequency & Percentage \\
\hline 1 & Individual & 25 & $25.5 \%$ \\
2 & Relational & 46 & $47 \%$ \\
3 & Collective & 26 & $26.5 \%$ \\
4 & Material & 1 & $1 \%$ \\
Total & & 98 & $100 \%$ \\
\hline
\end{tabular}

The results indicated that the most dominant identity was a relational identity with 46 or $47 \%$ occurrences, followed by collective identity with 26 or $26.5 \%$ occurrences, individual identity with 25 or $25.5 \%$ occurrences, and material identity with 1 or $1 \%$ occurrence. The domination of relational which then followed by collective identity is might be caused by the cultural value orientation in which most of the members of the classroom came from collectivistic society and some of them came from individualistic society.

Typically, the member of individualistic society sees themselves as more independent than others, while collectivistic society sees themselves as more interdependent with others. This results validated Smith (2011) in which he analyzed the individuals' capacity to choose between a range of personal and social identity, dependent upon the salience of alternative social context. He found that the effect of context is much greater among respondents from collectivistic culture. Another researcher found out that language is spoken in collectivist nation permit pronoun drop such as the omission of 'I' (Y. Kahima \& Kashima, 1998).

\section{Conclusion}

As reported on the previous part, all four types of identity have been found which were individual or personal, relational, collective, and material identities. These identities were represented through the use of various types of sentence, phrases, conjunction, greetings and its response, interlanguage, figures, non-verbal act, and material items. This finding proved Bloome et al., (2005) findings in which identity representation can be seen through the use of conjunction structure, valuable items, and authoritative figures. In fact, the findings of this research also found different ways of identity representation that is the use of greetings, non-verbal act, and interlanguage.

Munandar, L. O. A. H., Muhaimi, L., \& Nawawi, -. (2018). Textual representation of identity in classroom discourse. International Journal of Linguistics, Literature and Culture, 4(6), 53-62. 
Furthermore, at a basic level, these identity markers might be seen as normal sentences which function to instruct, order, or state an opinion. However, if it is seen through socio-cognitive perspective in which the ongoing process within the speaker's mind is reflected on their use of language, their identity was available to be traced. Like the situation in extract 1 in which the speakers did not familiar with the problem at hand. The speakers think of himself as someone that could not solve the problem and ended up asking for help from the other members of the classroom. This finding is in line with Atkins et al., (2005) in which individual or personal identity includes standards for behavior and decision making.

Moreover, the relational identity was found through the way the speakers provide instructions, order, guidance, and information in the form of a declarative, imperative, and exclamatory sentence. The most frequent occurrences of these were found on the teacher statements. By giving information, instruction, guidance, etc, the teacher might see himself as performing a teaching. Some instructions also came from the students in which the student instructed his group member. The differences between the instruction of the teacher and the instruction of the students can be seen from the scale of the effect of the instruction. At best, the students' instruction may affect their fellow students or their group.

As for collective identity, the sense of collectivity was found through the use of greetings and interlanguage. It was found that the speakers greeted the member of the class by using the Islamic greeting. Thus, the speaker indirectly includes her/him selves to the group of Muslim and this greeting was also replied Islamic which indicated that, whether they were aware or not, they already stated that they are followers of Islam. This process of including and excluding one's self in a social group was also used in analyzing the interlanguage as the identity marker for collective identity in which the speaker belongs to the group of a non-native speaker.

However, the use of interlanguage actually marked two types of identity. If the use of interlanguage was seen through 'process term' in which the individual that produced interlanguage is seen as an individual that steel learning a second or foreign language, then it marks the individual or personal identity. But if the use of interlanguage is seen through 'content term' in which the individual that produced it is seen as a group of a non-native speaker, then it marks collective identity. This finding is line with Vignoles et al., (2011) in which they stated that the distinction among individual, relational, and collective identity can be applied either to identity context contents or to identity processes. It seems that there still some needs for further analysis of the distinction between relational and collective identity.

The findings indicated that the most dominant identity was a relational identity with 46 or $47 \%$ occurrences, followed by collective identity with 26 or $26.5 \%$ occurrences, individual identity with 25 or $25.5 \%$ occurrences, and material identity with 1 or $1 \%$ occurrence. The domination of relational which then followed by collective identity might be caused by the cultural value orientation in which most of the members of the classroom came from collectivistic society and some of them came from individualistic society. Typically, the member of individualistic society sees themselves as more independent than others, while collectivistic society sees themselves as more interdependent with others.

\section{Conflict of interest statement and funding sources}

The authors declared that they have no competing interest. The study was financed by the authors.

\section{Statement of authorship}

The authors have a responsibility for the conception and design of the study. The authors have approved the final article.

\section{Acknowledgments}

This research would not have been possible without the grace of Allah for everything. He has bestowed on me and my family. I should especially thank my lectures for all their comments, feedbacks, and suggestions for the betterment and completion of this work, my mother whose love and guidance are with me in whatever I pursue. Also, I wish to thank my brother for his help during this research. 


\section{References}

Atkins, R., Hart, D., \& Donnelly, T. M. (2005). The association of childhood personality type with volunteering during adolescence. Merrill-Palmer Quarterly (1982-), 145-162.

Azhari, A. S. (2018). Speech Acts of Classroom Interaction. International Journal of Linguistics, Literature and Culture (IJLLC), 4(2), 24-45.

Bloome, D., Carter, S. P., Christian, B. M., Otto, S., \& Shuart-Faris, N. (2004). Discourse analysis and the study of classroom language and literacy events: A microethnographic perspective. Routledge.

Fearon, J. D. (1999). What is identity (as we now use the word). Unpublished manuscript, Stanford University, Stanford, Calif.

Flick, U. (2014). An introduction to qualitative research. Sage.

Kashima, E. S., \& Kashima, Y. (1998). Culture and language: The case of cultural dimensionsand personal pronoun use. Journal of Cross-Cultural Psychology, 29(3), 461-486. https://doi.org/10.1177\%2F0022022198293005

Mangum, M., \& Block, R. (2018). Social Identity Theory and Public Opinion towards Immigration. Social Sciences, 7(3), 41. https://doi.org/10.3390/socsci7030041

Norton, B., \& Toohey, K. (2011). Identity, language learning, and social change. Language teaching, 44(4), $412-446$. https://doi.org/10.1017/S0261444811000309

Overton, J. (2006). Teacher identity and power relationships in contexts of change: A case study of teachers.

Rymes, B. (2015). Classroom discourse analysis: A tool for critical reflection. Routledge.

Schwartz, S. J., Luyckx, K., \& Vignoles, V. L. (Eds.). (2011). Handbook of identity theory and research. Springer Science \& Business Media. https://doi.org/10.1007/978-1-4419-7988-9

Smith, P. B. (2011). Cross-cultural perspectives on identity. In Handbook of identity theory and research (pp. 249265). Springer, New York, NY. https://doi.org/10.1007/978-1-4419-7988-9_11

Tajfel, H., \& Turner, J. C. (1986). The Social Identity Theory of Intergroup Behavior, Psychology of Intergroup Relations, edited by Stephen Worchel and William G. Austin. Chicago: Nelson-Hall, 724.

Turner, J. C. (1982). Towards a cognitive redefinition of the social group. Social identity and intergroup relations, 15-40.

van Dijk, T. A. (1993). Principles of Critical Discourse Analysis. Discourse \& Society, 4(2), $249-283$. https://doi.org/10.1177/0957926593004002006

van Dijk, T. A. (2017). Socio-cognitive discourse studies. In The Routledge handbook of critical discourse studies (pp. 26-43). Routledge.

Vignoles, V. L., Schwartz, S. J., \& Luyckx, K. (2011). Introduction: Toward an integrative view of identity. In Handbook of identity theory and research (pp. 1-27). Springer, New York, NY. https://doi.org/10.1007/9781-4419-7988-9_1

Munandar, L. O. A. H., Muhaimi, L., \& Nawawi, -. (2018). Textual representation of identity in classroom discourse. International Journal of Linguistics, Literature and Culture, 4(6), 53-62. https://doi.org/10.21744/ijllc.v4n6.407 


\section{Biography of Authors}

\begin{tabular}{|c|c|}
\hline & $\begin{array}{l}\text { La Ode Alfin Haris Munandar was born in Ampenan, } 3^{\text {rd }} \text { February } 1991 \text {. He } \\
\text { completed his study from elementary school to the secondary level of study in his } \\
\text { birthplace. In } 2012 \text { he completed his bachelor degree at Department of English } \\
\text { Language and Art at IKIP Mataram. He continues to study to Master Programme of } \\
\text { English Language at Mataram University. } \\
\text { He can be contacted via e-mail: harisalfin91@gmail.com }\end{array}$ \\
\hline & $\begin{array}{l}\text { Lalu Muhaimi was born in Central Lombok, } 16^{\text {th }} \text { April 1960. He completed his study } \\
\text { from elementary school to the secondary level of study in his birthplace. In } 1985 \text { he } \\
\text { completed his bachelor degree at Department of English Literature at Jember } \\
\text { University. He continues to study to Master Programme of English Language and } \\
\text { Literature Education at the State University of Surabaya in } 2011 \text {. He Completed Doctor } \\
\text { Programme of Department of English Language and the Literature Education at the } \\
\text { State University of Surabaya in 2016. Now, he is a lecturer at the undergraduate and } \\
\text { master programme of English Language Education at Mataram University. He can be } \\
\text { contacted via e-mail: lalu_muhaimi@unram.ac.id or by visiting him directly at the } \\
\text { Secretariat of the Educational Administration Master Program, Building } 1 \text { Floor } 1 \mathrm{st} \\
\text { FKIP Mataram University, Jln Majapahit No. 61 Mataram. }\end{array}$ \\
\hline & $\begin{array}{l}\text { Nawawiwas born in East Lombok, } 31^{\text {st }} \text { December } 31,1962 \text {. He completed the study of } \\
\text { elementary education up to high school in his hometown. Furthermore, in } 1987 \text { he } \\
\text { completed bachelor programme of Department of English Language Education at } \\
\text { Mataram University. In } 1998 \text { he completed a master degree at Deakin University, } \\
\text { Melbourne Australia. He continues to study at Doctor Programme of Language } \\
\text { Education at the State University of Jakarta. Now, he is a lecturer at the undergraduate } \\
\text { and master programme of English Language Education, at Mataram University. He can } \\
\text { be contacted via e-mail Nawawi1962@yahoo.com. }\end{array}$ \\
\hline
\end{tabular}

